\title{
From seasonal patterns to a reference situation in an estuarine environment: Example of the small fish and shrimp fauna of the Gironde estuary (SW France)
}

\author{
Jérémy Lobry ${ }^{\mathrm{a},{ }^{\star}}$, Mario Lepage ${ }^{\mathrm{a}}$ and Eric Rochard ${ }^{\mathrm{a}}$
}

\begin{abstract}
${ }^{a}$ Cemagref, Groupement de Bordeaux, Estuarine Ecosystems and Diadromous Fish Research Unit, 50 avenue de Verdun, 33612 Cestas Cedex, France

*: Corresponding author : IFREMER, Département EMH (Ecologie et Modèles pour l'Halieutique), Rue de L'Ile d'Yeu, BP 21105, 44311 Nantes Cedex 3, France ; jeremy.lobry@ifremer.fr
\end{abstract}

\begin{abstract}
Detecting changes in animal communities suggests that a reference situation exists. It is a particularly difficult task in estuarine environments that are complex and fluctuate with time. Effects of human pressures are difficult to assess due to the scarcity or even the lack of evaluation and monitoring systems. In order to detect anomalies in the functioning of the system and to identify effects of perturbations upon populations and communities, it is necessary to analyse the dynamics in order to infer a reference state. This work aims to describe an approach based on K-Tab analyses and allows to define an average situation called "compromise" which is then compared to a single year of data. In this situation, the Gironde estuary, which has been monitored monthly from the 1980s, appears to be a very relevant case study. This paper focuses on spatial and temporal variations in species composition of fish and shrimp assemblages in the mesohaline and oligohaline stretches of the estuary and demonstrates a strong downstream-upstream structuring of species composition. Seasonal structure of the biological assemblages is highlighted and a biomass transfer in the water column between summer and winter is noticed. The habitat suitability is mainly discussed in terms of hydraulic regime but could also be discussed in terms of trophic resources availability. No important differences in the spatial distribution of the fish and shrimp assemblages can be detected between the year 2000 and the reference situation however the method is probably more relevant when detecting trends rather than single anomalies in the structure of the assemblages.
\end{abstract}

Keywords: STATIS; spatial pattern; correspondence analysis; Gironde estuary; fish and shrimp assemblages dynamics 


\title{
From seasonal patterns to a reference situation in an estuarine environment: example of the small fish and shrimps fauna of the Gironde estuary (SW France).
}

\author{
Jérémy Lobry *,1 , Mario Lepage, Eric Rochard \\ Cemagref, Groupement de Bordeaux, Estuarine ecosystems and Diadromous fish research unit, \\ 50 avenue de Verdun, 33612 Cestas Cedex, France. \\ * Corresponding author \\ ${ }^{1}$ Present address: Jérémy Lobry, IFREMER, Département EMH (Ecologie et Modèles pour \\ l'Halieutique), Rue de l'Ile d'Yeu, BP 21105, 44311 NANTES Cedex 3, France \\ Tél :+ $33(0) 240374212$ \\ Fax :+ $33(0) 240374075$ \\ E-mail : jeremy.lobry@ifremer.fr
}

\begin{abstract}
Detecting changes in animal communities suggests that a reference situation exists. It is a particularly difficult task in estuarine environments that are complex and fluctuate with time. Effects of human pressures are difficult to assess due to the scarcity or even the lack of evaluation and monitoring systems. In order to detect anomalies in the functioning of the system and to identify effects of perturbations upon populations and communities, it is necessary to analyse the dynamics in order to infer a reference state. This work aims to describe an approach based on K-Tab analyses and allows to define an average situation called "compromise" which is then compared to a single year of data. In this situation, the Gironde estuary, which has been monitored monthly from the 1980s, appears to be a very relevant case study. This paper focuses on spatial and temporal variations in species composition of fish and shrimps assemblages in the mesohaline and oligohaline stretches of the estuary and demonstrates a strong downstream-upstream structuring of species composition. Seasonal structure of the biological assemblages is highlighted and a biomass transfer in the water column between summer and winter is noticed. The habitat suitability is mainly discussed in terms of hydraulic regime but could also be discussed in terms of trophic resources availability. No important differences in the spatial distribution of the fish and shrimps assemblages can be detected between the year 2000 and the reference situation however the method is probably more relevant when detecting trends rather than single anomalies in the structure of the assemblages.
\end{abstract}

Keywords: STATIS; spatial pattern; Correspondence Analysis; Gironde estuary; fish and shrimps assemblages dynamics

\section{Introduction}

Estuarine ecosystems are typically characterised by large and drastic fluctuations of the physicochemical conditions of the environment at various spatial (e.g. upstream-downstream salinity gradient, vertical turbidity gradient) and temporal (from tidal to interannual scale) levels. Moreover, these ecosystems are often subjected to important anthropogenic pressures such as fishing, harbour activities, dredging or industrial pumping. The structure and dynamics of biological communities result from the interactions of all the above elements and are thereby marked by a high variability and a strong spatial and seasonal heterogeneity (Mc Lusky, 1981; Claridge et al., 1986; Potter et al., 1986).

It is particularly true for the small fish fauna (Claridge et al., 1986; Potter et al., 1986). This particular group is probably the most important part of the fish populations in the large estuaries of the European Atlantic coast (Rebelo, 1992; Elliott and Dewailly, 1995; Thiel et al., 1995). The small fish and shrimps fauna is of noteworthy interest in estuarine and coastal systems when considering fisheries aspect (Elliott et al., 1990; Costa et al., 2002; Le Pape et al., 2003a) and it also constitutes an essential link in the estuarine food web. 
In this context, recent approaches in aquatic resources management, such as the Ecosystem Approach to Fisheries (Garcia et al., 2003) and the European Water Framework Directive (WFD) adopted in 2000 (EU, 2000), imply a solid knowledge of seasonal patterns in small fish and shrimps assemblages. These frameworks require well-structured approaches in monitoring the aquatic ecosystem, and require integrated research on spatial and temporal patterns within the aquatic ecological assemblages. However, because of the lack in available knowledge the development of classification tools is hindered.

The aim of the present study was to investigate the spatial patterns and temporal variation of the structure of small fish and shrimps assemblages in an estuarine environment. To do this, it was proposed to use a particular multivariate data analysis technique: the ACTSTATIS method, also known as the STATIS method (Lavit et al., 1994). The STATIS method aims to investigate three-dimensional data analysis and to compare configurations of different data observed at the same time or at the same locations (Lekve et al., 2002). It has been used in several studies in aquatic ecology. For example, Gaertner et al. (1998) proposed it to study the stability of spatial organization of demersal assemblages in terms of fish species composition; Blanc et al. (1998) studied the temporal stability of spatial fish population structures of southern France by analysing series of totally paired faunistic tables using particular STATIS methods; and Lekve et al. (2002) used this approach to analyse species richness of fish along the Norwegian Skagerrak coast. The method has been used in relatively few estuarine studies, but Baran (1995) proposed it to focus on the spatio-temporal dynamics of fish assemblages in a Guinean estuary. Within this paper, it is demonstrated that, if performed on time X station X species three-way datasets, then this technique allows to deduce an "ordinary pattern" for the fish and shrimps dynamics in an estuary by focusing on the stable part of fish and shrimps assemblages variations in space and time. It is also demonstrated that the pattern obtained is characteristic to that of a reference situation.

The example of the small fish and shrimps of the Gironde estuary is presented here as a case study. Their dynamics in the Gironde estuary have not been described before at the assemblage level. It is therefore proposed to investigate how a STATIS approach can (a) characterise the seasonal patterns of this assemblages that should be observed during an ordinary year in order to (b) deduce a reference pattern from the above analysis and then (c) compare this kind of reference situation to any given situation observed in the estuary at the same scale.

\section{Materials and methods}

\subsection{Study site}

The Gironde estuary is located SW of France (Fig. 1). The climate of the region is temperate and under oceanic influence. Variability of the water temperature is moderate (between $2{ }^{\circ} \mathrm{C}$ in January and $26^{\circ} \mathrm{C}$ in August) and monthly rainfall fluctuates between $50 \mathrm{~mm}$ in summer and $100 \mathrm{~mm}$ in winter (Tank et al., 2002). The river drainage has a seasonal precipitation pattern characterised by high discharge periods in fall (rain) and spring (snowmelt) and low ones in late summer. Thus, during a typical year (ex. 2000, Fig. 2), temperature, salinity and river flow values in the estuary exhibit a clear seasonality with low values of water flow in summer (July-August-September) and high values of temperature and salinity during this period.

Moreover, the Gironde estuary is the biggest estuary in France and the largest in Western Europe (Salomon, 2002; Lobry et al., 2003). Its surface area is approximately $625 \mathrm{~km}^{2}$ at high tide. Between the ocean (seaward of a transect drawn between Pointe de Grave - Pointe de Suzac; Fig. 1) and the upstream salinity limit (Bec d'Ambès), it is $76 \mathrm{~km}$ long. The watershed covers $81,000 \mathrm{~km}^{2}$ and the mean annual rate of freshwater discharge is around $1,000 \mathrm{~m}^{3} \cdot \mathrm{s}^{-1}$ (Sottolichio and Castaing, 1999). There is a more or less permanent turbidity maximum zone (silt plug) with suspended matter concentrations of about $1 \mathrm{~g} . \mathrm{l}^{-1}$ at the surface and 10 g. $1^{-1}$ near the bed (Sottolichio and Castaing, 1999). Owing to the turbidity, primary production is low, however, there is a large zooplankton biomass (Castel, 1993). 


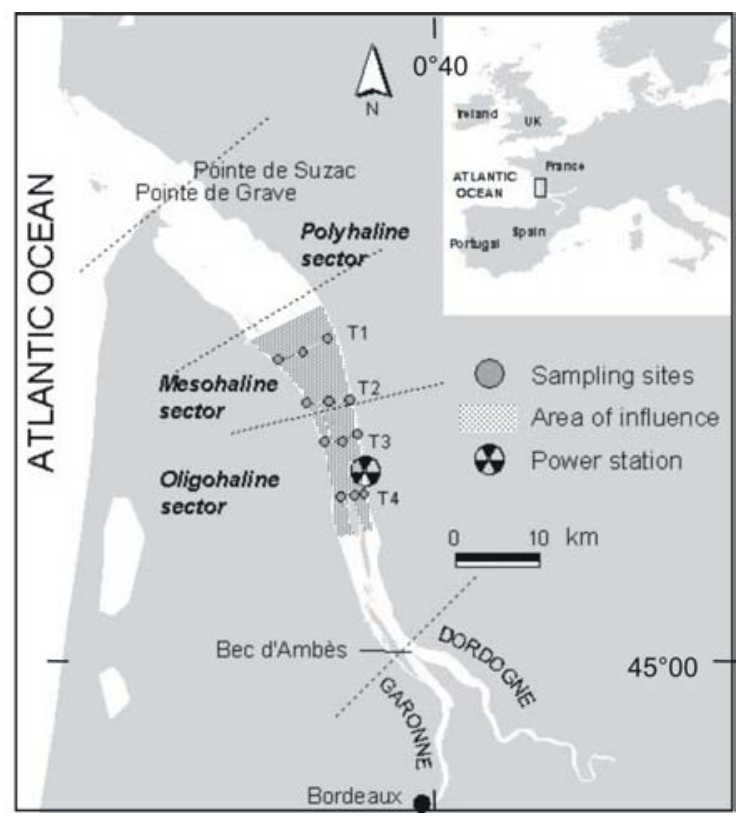

Figure 1. Location of the sampling stations in the Gironde estuary. T2=Transect 2.

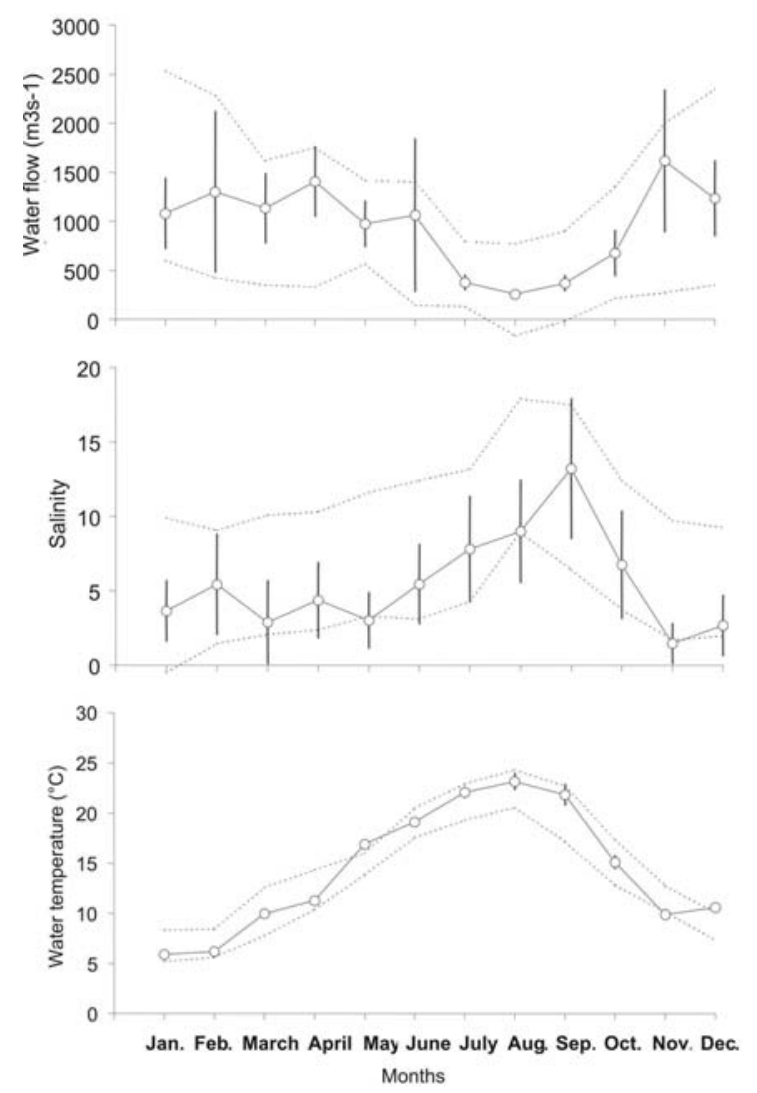

Figure 2. Mean values (o) and standard deviations (-o-) of water flow (top), salinity (middle) and water temperature (bottom) measured in the samples during the year 2000. Dotted lines indicate mean values +/- standard deviations for the reference period (1991-98).

The Gironde estuary is notable amongst French and European estuaries as having a long-term (25 years) biological database. Its small fish and shrimps fauna have been sampled monthly since the early 1980s in order to assess the impact of a newly constructed Nuclear Power Plant (Elie and Rochard, 1994; Pronier and Rochard, 1998; Lobry et al., 2003). Initial monitoring focussed upon the juvenile fish and shrimps species and lifestages of larger fish species, with one of the main objectives of the monitoring programme was to detect the impact of power plant water intake and water temperature increase at the population or community level. An assessment of the affect upon smelt Osmerus eperlanus was described by Pronier and Rochard, (1998) though the impact of the power station was inconclusive. In the case of the Gironde estuary it was possible to refer to data from 1979 (preliminary surveys were processed before the construction of the Nuclear power plant CTGREF, 1979, unpublished data) to characterise "historical" reference conditions.

\subsection{Sampling design}

Transect surveys have been undertaken since 1979 in order to monitor the smaller components of the estuarine fauna around the Blayais nuclear power plant (Elie and Rochard, 1994; Pronier and Rochard, 1998; Lobry et al., 2003). Many changes to the sampling protocol have occurred between 1979 to 1991, though the fishing gear has remained similar. For example, the number of sampling sites, number of sampling stations, frequence of the surveys, sampling duration and sampling time according to the tidal cycle have varied. In particular, before 1991, the monitoring programme included only one transect. Since 1991, the sampling protocol has been standardized. Transect surveys have been undertaken at least once a month. 
The sampling sites are located within four transects (numbered from 1 to 4 downstream to upstream) which cross the estuary in the mesohaline and in the oligohaline zones (Fig. 1). Each transect consists of three sites, one close to each bank and one on the middle axis of the estuary. On each site, simultaneously, one fishing sample is made near the surface and one near the bottom. Surface samples are taken using two $4.0 \times 1.0 \mathrm{~m}$ rectangular frame nets fitted both sides of the boat. The subconical nets have a stretched mesh size of $18 \mathrm{~mm}$ in the main section and $2.8 \mathrm{~mm}$ in the terminal section. For the benthic samples, a dragnet with a $2.0 \times 1.2 \mathrm{~m}$ frame is used. Runners keep the frame $0.2 \mathrm{~m}$ above the bed. The net meshes are identical to those used for surface samplings. Sampling lasts five minutes and is performed in daytime, between the halfway stage of the flood tide and high tide slack, with the gear being towed against the current. The fauna sampled consists mainly of small fish species or of the younger stages of larger species (table I) with all fish caught preserved in buffered formalin. The area of of the sampled zone (about $190 \mathrm{~km}^{2}$ ) represents about $30 \%$ of the total surface of the estuary. Limited and selective sampling surveys with the same gears and protocol have been carried out both upstream and downstream of the sampled area. They show that the fish assemblages are relatively similar (Cemagref, unpublished data). The small fish fauna sampled by the above protocol is thus typical of the major part of the haline estuary. The data was inputted to Cemagref's GIRPOISS database which has been running since 1979. Within this study, only data collected between 1991 and 1998 was analysed.

The above analysis also took into account the lifestage of the individuals sampled. Thus, the word "species " employed in this paper refers to the aggregate data species $x$ lifestage (table I). Moreover, for the shrimp Palaemon longirostris we considered the characteristic ovigerous or not ovigerous.

The main focus of the present study is to identify and characterize the stable part and the variable part of the spatial structure of the assemblages through years. It has been highlighted in similar studies (Baran, 1995; Blanc and Beaudou, 1998; Blanc et al., 1998; Gaertner et al., 1998) that in order to avoid an excess of zero entries in the data matrices, then those species deemed to be rare were excluded from the analysis as they provide little information about spatial and temporal structure of the assemblages (Frontier, 1983). In this study, we exclude species that occurred in less than $1 \%$ of the samples. Twenty-two species remained (table I).

For each sample, abundance of species was expressed as the number of individuals per $1,000 \mathrm{~m}^{3}$ of filtered water. The data were $\log$-transformed by using:

$$
X \rightarrow \ln (X+1)
$$

Surface and bottom temperature and salinity data were collected during transect surveys using a multiparameter probe IDROMAR IM51-IM201. Flow data come from the Bordeaux Harbour Authority. 
Table I. Species codes used in the study. Lifestage corresponds to age for fish and to the characteristic ovigerous or not ovigerous. CA: diadromous species; $M$ : marine species; $F W$ : freshwater adventitious species; ER: truly estuarine resident species (from Lobry et al. 2003). * species not selected in the STATIS analysis.

\begin{tabular}{|c|c|c|c|c|c|}
\hline & $\begin{array}{l}\text { Species } \\
\text { code }\end{array}$ & Species name & English name & Lifestage & $\begin{array}{l}\text { Ecological } \\
\text { guild }\end{array}$ \\
\hline \multirow{24}{*}{ 雳 } & ALA & Alosa alosa & Allis shad & $0+$ & $\mathrm{CA}$ \\
\hline & ALF & Alosa fallax & Twaite shad & $0+$ & $\mathrm{CA}$ \\
\hline & ANC & Engraulis encrasicolus & European anchovy & $0+$ & $\mathrm{M}$ \\
\hline & ANG & Anguilla anguilla & European eel & $0+$ & $\mathrm{CA}$ \\
\hline & $\mathrm{CCO}^{*}$ & Cyprinus carpio & Common carp & all & FW \\
\hline & ANGJ & Anguilla anguilla & Glass eel & & CA \\
\hline & EPEA & Osmerus eperlanus & Smelt & $1+$ & $\mathrm{CA}$ \\
\hline & EPEJ & Osmerus eperlanus & Smelt & $0+$ & $\mathrm{CA}$ \\
\hline & EPI & Gasterosteus aculeatus & Three-spined stickleback & all & FW \\
\hline & FLEA & Platichthys flesus & Flounder & $1+$ & $\mathrm{CA}$ \\
\hline & FLEJ & Platichthys flesus & Flounder & $0+$ & $\mathrm{CA}$ \\
\hline & GOBA & Pomatoschistus minutus & Sand goby & $1+$ & ER \\
\hline & GOBJ & Pomatoschistus minutus & Sand goby & $0+$ & ER \\
\hline & LOU & Dicentrarchus sp. & Bass & $0+$ & $\mathrm{M}$ \\
\hline & LPM* $^{*}$ & Petromyzon marinus & Sea lamprey & $0+$ & $\mathrm{CA}$ \\
\hline & LPR* & Lampetra fluviatilis & River lamprey & $0+$ & $\mathrm{CA}$ \\
\hline & MUPA & Liza ramada & Thin-lipped grey mullet & $1+$ & $\mathrm{CA}$ \\
\hline & MUPJ & Liza ramada & Thin-lipped grey mullet & $0+$ & $\mathrm{CA}$ \\
\hline & PES* & Lepomis gibbosus & Pumpkinseed & all & FW \\
\hline & SAN* & Stizostedion lucioperca & Pikeperch & all & FW \\
\hline & SOL & Solea vulgaris or $S$. senegalensis & Sole & $0+$ & M \\
\hline & SPT & Sprattus sprattus & Sprat & $0+$ & M \\
\hline & SYNA & Syngnathus rostellatus & Nilsson's pipefish & $1+$ & M \\
\hline & SYNJ & Syngnathus rostellatus & Nilsson's pipefish & $0+$ & M \\
\hline \multirow{3}{*}{ 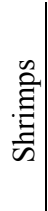 } & CRBN & Palaemon longirostris & White shrimp & $\begin{array}{c}\text { not } \\
\text { ovigerous }\end{array}$ & ER \\
\hline & CRBO & Palaemon longirostris & White shrimp & ovigerous & ER \\
\hline & CRG & Crangon crangon & Brown shrimp & all & $\mathrm{M}$ \\
\hline
\end{tabular}

\subsection{Data processing}

ACT-STATIS method is a data analysis technique that computes Euclidian distances between configurations of the same observations obtained in $\mathrm{K}$ different circumstances, and thus handles three-dimensional data as a set of K matrices (Lavit et al., 1994). Within the analysis the various tables represent the 8 years of sampling between 1991 and 1998. Each table consists of a stations $\mathrm{x}$ species matrix. The STATIS method allowed us to make an overall study of these tables, thus enabling the investigation of the spatial patterns of temporal variation of the structure of fish and shrimps assemblages in the estuary. The general functioning principle of STATIS is illustrated in Fig. 3.

By this method the similarity between the tables is first quantified by the RV coefficient (" $\mathrm{R}$ " for correlation and " $\mathrm{V}$ " for vectorial), which is a multidimensional correlation coefficient comparable to the Pearson correlation coefficient. Their values range from 0 to 1 . 
Secondly, common patterns of temporal variability may be summarised into a table called "compromise". The compromise table is constructed as a linear combination of the different tables in proportion to their weights:

$$
\mathrm{X}=\sum_{\mathrm{i}=1}^{\mathrm{K}} \alpha_{\mathrm{i}} \mathrm{X}_{\mathrm{i}}
$$

where $\alpha_{i}$ are the weights of the tables $\mathrm{X}_{i}$ calculated by using the $\mathrm{k}$ coefficients of the first eigenvector obtained after the diagonalisation of the matrix of inter-matrix scalar products with the additional constraint that

$$
\sum_{i=1}^{k} \alpha_{i}^{2}=1
$$

Within the STATIS approach the table weights are selected so as to maximize the variability of the spectral decomposition of X. In the construction of the compromise table, a greater importance is given to tables which have similar structures and lesser importance to the other tables (Gaertner et al., 1998).

Finally, a RV coefficient, which measures the correlation of a given table with the compromise, may be computed (the so-called square cosine, see Blanc et al., 1998 for further details).

As proposed by Gaertner et al. (1998), we used a method that couples the STATIS multitable approach with the logic of Correspondence Analysis (CoA). CoA allowed us to focus on species associations rather than species abundance by centring by rows and by columns. It is required when the point is studying gradients. CoA version of STATIS enabled us to focus on the compromise rather than on variability. This strategy was first developed by Foucart (1978) for $\mathrm{k}$ contingency tables with the same individuals (e.g. same sampling stations) and variables. It was then used for tables without the same number of individuals. A problem is that the correspondence analysis of a table defines the weighting for rows and columns by double averaging whereas Principal Component Analysis (PCA) does not. So, the variant proposed in the present study needed several transformations of the initial tables based upon the example by Gaertner et al. (1998).

\subsection{Construction of the reference situation}

It was proposed to construct a table describing the reference situation by computing a linear combination of the different initial tables (without STATIS-CoA transformations) in proportion to the weights $\left(\alpha_{\mathrm{i}}\right)$ calculated by STATIS analysis. Contrary to the compromise table, this table (so-called "reference table") is in the same unit as initial tables and can be compared directly to any other stations $\mathrm{x}$ species matrix obtained with the same sampling protocol. CoA of this reference table was performed.

A factor-based ascendant hierarchical classification (AHC) was constructed. This technique was used to classify a set of individuals (the stations in our case) characterized by their prime factorial coordinates, as created by a factorial analysis procedure. The aggregation criterion used was Ward's criterion that states that merging AHC clusters should be focused on minimizing the added interclass variance.

In order to consider the variability in the positions of species on the factorial map, we plotted them for the different years of the reference period 1991-98 as illustrative variables. The scattering of the plots is related to the variability of the position of species around the compromise and reference factorial planes. Additionally, Euclidean distances D between each illustrative plot and the plot of the reference plane can be computed using the factorial coordinates of each plot. Minimum distance, mean distance or standard deviation of the distances between plots for each species can be viewed as examples of measures of the variability in the positions of species on the map.

Finally, as an example, we compared data obtained in 2000 to data of the reference table. A RV coefficient was calculated and a projection of the data obtained in 2000 onto the reference table was performed. Euclidean distances between plots for each species on the reference factorial plane and plots for the species of 2000 were calculated as a specific measure of deviation from the reference. 
STATIS analyses were performed using ADE-4 software (Thioulouse et al., 1997): ADE-4 version 2001-CCNRS 1995-2000. CoA and AHC of the reference table were performed by Spad 4.01 (C) CISIA-CERESTA, 1987-1999.

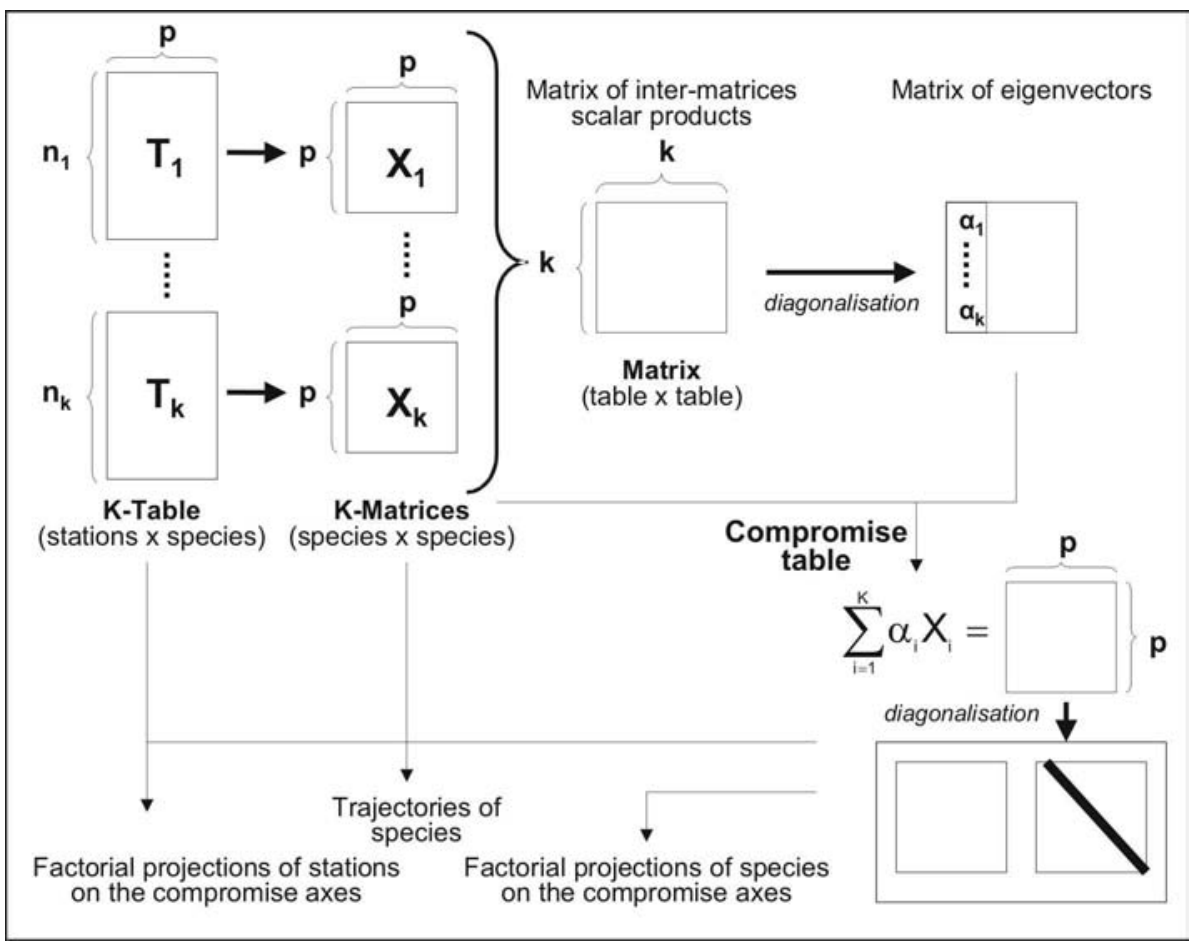

Figure 3. Simplified scheme of the principle of the STATIS method. For the survey $i:$ Ti=initial table; $p$ $=$ number of species; $n i=$ number of stations sampled; Xi=matrix of scalar products between species; $\alpha i=$ coefficients of the first eigenvector (from Gaertner et al., 1998).

\section{Results}

\subsection{Interstructure analysis}

The numerical parameters associated with STATIS analysis processed on the data are listed in table II. The diagonalisation of the matrix of inter-matrix scalar products (RV matrix) provides the main axis. The first one represents more than $77 \%$ of the inertia. The projection of each table on this axis gives us a good idea of the similarity between tables (Fig. 4).

Configuration of the 8 tables is relatively homogeneous but there are 2 separate groups. The construction of a compromise was thus justified. The 'weights' values are between 0.33 and 0.37 so the contribution of each year of sampling to the construction of the compromise table is well balanced. The squared cosine between the third table (1993) and the compromise table is particularly weak (Table II) which indicates that the year 1993 is not well represented by the compromise. 


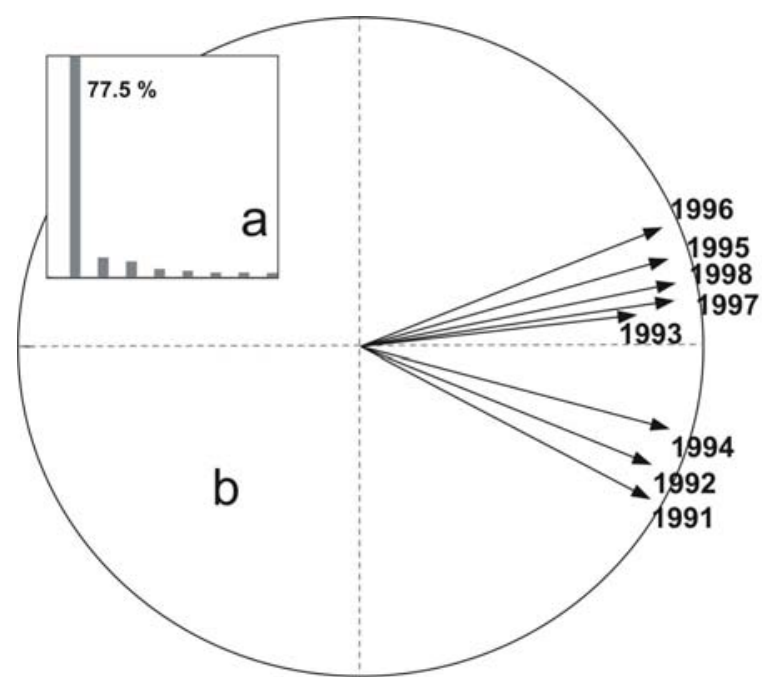

Figure 4. Interstructure results of the STATIS analyses processed on faunal data. (a) Histogram of eigenvalues generated by the diagonalization of the RV matrix and (b) projections of the eight tables (years) on the interstructure axes 1 and 2.

Table II. Description of the structure of tables. Values of the parameters associated with the STATIS analysis processed on the data. $R V=$ Vectorial correlation between tables; Weights $=$ Weights of operators in the compromise; NS norm $2=$ Square norm (Hilbert-Schmidt) of operators; Cos $2=$ Square cosine between operator and approximated compromise.

\begin{tabular}{|c|c|c|c|c|c|c|c|c|}
\hline $\begin{array}{c}\text { Year of } \\
\text { sampling }\end{array}$ & $\begin{array}{c}\text { Number } \\
\text { of rows }\end{array}$ & $\mathbf{R V}$ & & & & $\begin{array}{c}\text { Weights } \\
\left(\alpha_{k}\right)\end{array}$ & $\begin{array}{c}\text { NS } \\
\text { norm }^{2} \\
\end{array}$ & $\operatorname{Cos}^{2}$ \\
\hline 1991 & 263 & 1 & & & & 0.34 & 0.92 & 0.35 \\
\hline 1992 & 256 & $0.788 \quad 1$ & & & & 0.34 & 0.63 & 0.43 \\
\hline 1993 & 288 & 0.6490 .570 & & & & 0.33 & 0.49 & 0.20 \\
\hline 1994 & 287 & 0.8210 .7830 .747 & & & & 0.36 & 0.43 & 0.45 \\
\hline 1995 & 287 & 0.6890 .6670 .6960 .759 & 1 & & & 0.36 & 0.23 & 0.37 \\
\hline 1996 & 263 & 0.6210 .6930 .6750 .7010 .826 & 1 & & & 0.35 & 0.21 & 0.47 \\
\hline 1997 & 288 & 0.7370 .7650 .6590 .7560 .844 & 40.846 & 1 & & 0.37 & 0.28 & 0.47 \\
\hline 1998 & 261 & 0.6900 .7420 .7270 .7940 .835 & 50.838 & 0.845 & 1 & 0.37 & 0.26 & 0.55 \\
\hline
\end{tabular}

\subsection{Compromise and reference table analyses}

Analyses of the compromise and reference tables provide histograms of eigenvalues (Figs. 5a and 6a). In the first case, the eigenvalues of the six first axes can explain $53.1 \%$ of the total variance whereas in the second case, $53.3 \%$ of the total variance can be explained by only 2 axes. However, as the first dimension is clearly dominating in each case, we decided to comment only the first factorial planes F1xF2 which accounted for $26.4 \%$ of the variance of the compromise table and $53.3 \%$ of the variance of the reference table. In order to describe the structure, the scores of the centres of gravity of each group of sampling sites respect to the month of sampling, the position of the site in the estuary and the position of the sampling in the water column were plotted on the factorial maps (Figs. 5b and 6b). The patterns observed are similar in both cases. They reveal a double structuring in time and space. Along the first axis (F1), samples carried out during winter months are placed opposite samples made during summer months. The second axis distinguishes spring and fall surveys. An upstreamdownstream gradient appears along F1. Furthermore, we noticed that the centroid loading of surface sites is plotted on the right side of the graph associated with the centroid loading of downstream stations and those of riverbed sites is plotted on the left side associated with upstream stations. 


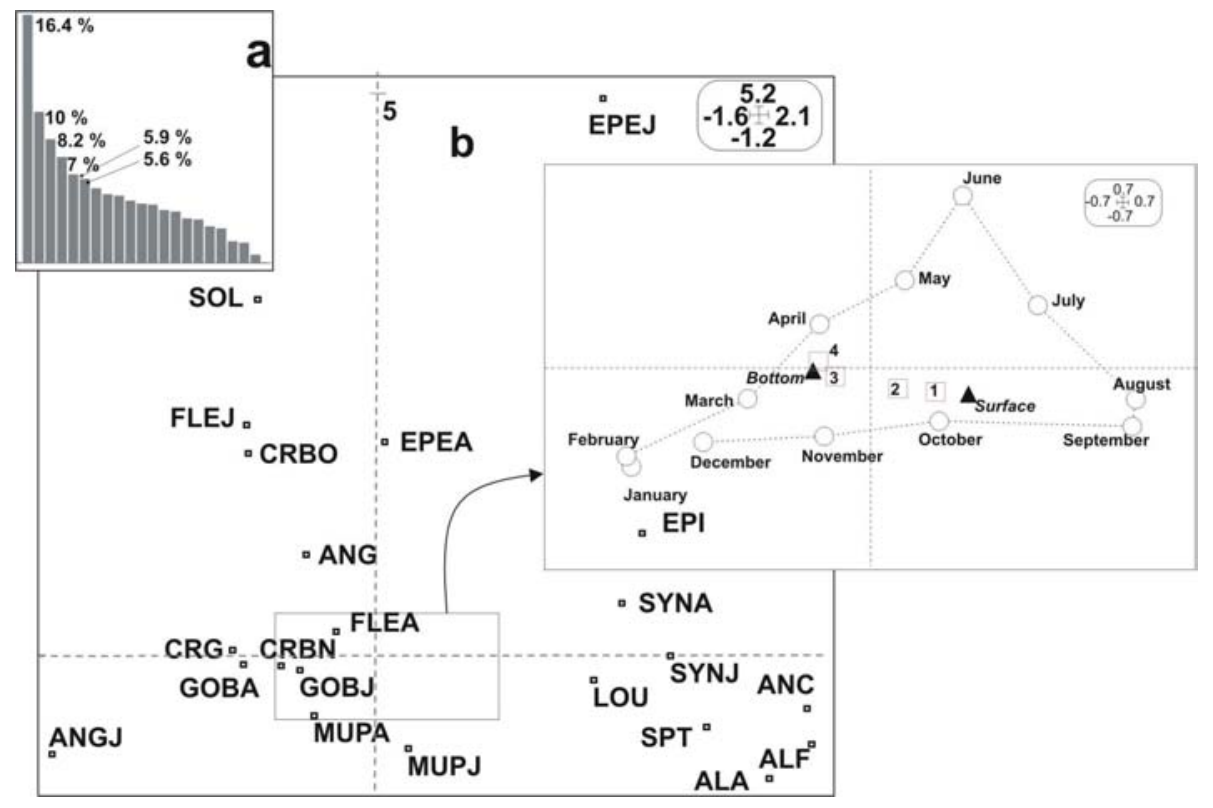

Figure 5. Compromise analysis. (a) Histogram of eigenvalues of the compromise CoA with percentage of inertia for the first six axes. (b) Projections on the first compromise plane of the species codes and of the centres of gravity of each sampling station respect to the month of sampling $(O)$, the transect on which the station is located in the estuary ( $\square$ ) and the position of the sampling in the water column ( $\mathbf{\Delta})$.

The factor-based AHC performed on the reference situation matrix revealed 3 groups (Fig. 6b, Table III). The first one, on the left of the factorial plane, is characterised by samples made in winter (between November and March). The second group is representative of samples made in spring and early summer (from April to June) and samples collected between late summer and early autumn (between July to October) are distinctive of the last class.

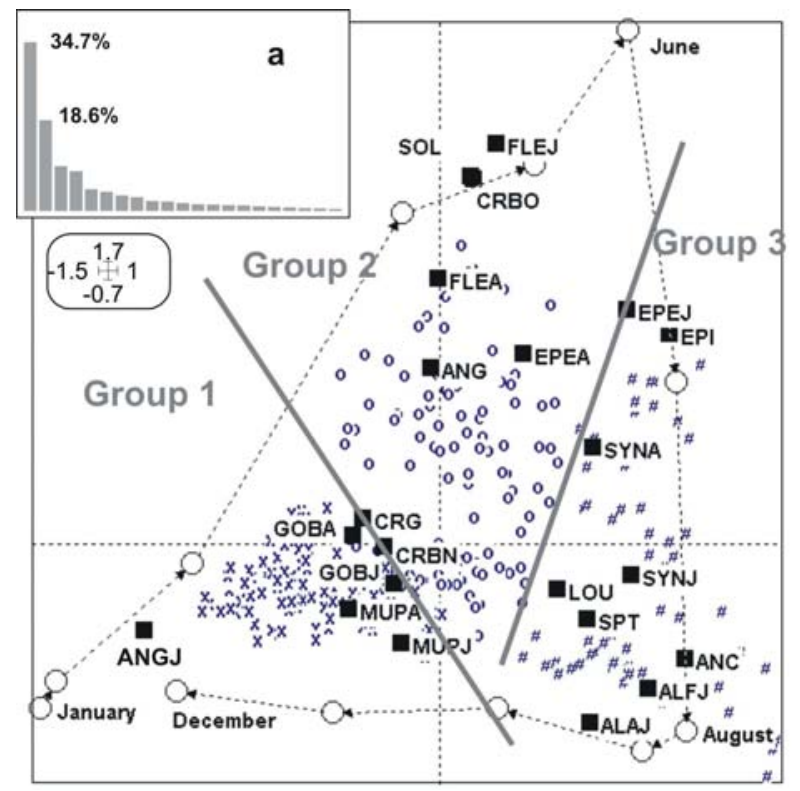

Figure 6. CoA processed on the reference table. (a) Histogram of eigenvalues of the CoA with percentage of inertia for the first two axes. (b) Projection of the species codes (n), of the centres of gravity of each sampling station respect to the month of sampling $(O)$ and of the sampling stations. Symbols for the station are differentiated in relation to the "ecological season" of sampling: winter (x), spring (o) and summer/autumn (\#). See text and Table III for further details. 
Table III. Results of the AHC performed on the reference situation matrix. For each group, the table presents the characteristic season of sampling (Distinctive season) and the most representative species of samples in the group on looking at their test values (Associated species).

\begin{tabular}{cll}
\hline AHC group & Distinctive season & Associated species \\
\hline 1 & Winter (November to March) & Glass eel, \\
& & Thin-lipped grey mullet \\
& Goby, \\
& & Flounder, \\
& White shrimp, \\
& Brown shrimp \\
& & \\
& \multirow{2}{*}{ Spring (April to June) } & Ovigere white shrimp, \\
& & Eel, \\
& & Smelt \\
& & Sole, \\
& & Young flounder \\
3 & \multirow{2}{*}{ Summer/Autumn (July to October) } & Bass, \\
& & Allis shad, \\
& & Twaite shad, \\
& Anchovy, \\
& & Three-spined stickleback, \\
& & Sprat, \\
& & Nilsson's pipefish \\
\hline
\end{tabular}

The variables (species) were also projected on the planes (Figs $5 \mathrm{~b}$ and $6 \mathrm{~b}$ ). The species codes are plotted by averaging on the stations they were sampled and can be associated with the 3 groups of samples resulting from the classification procedure (Table III). Glass eel (ANGJ) is plotted quite separately from other species on the left bottom of the graph. Near the origin of the axes, with the thin-lipped grey mullet (MUPA and MUPJ), there is a group of benthic and demersal species: goby (GOBA and GOBJ), flounder (FLEA), white shrimp (CRBN) and brown shrimp (CRG). These above species are associated with group 1 of the AHC. Species that appear on the right bottom side of the graph are mainly pelagic species such as bass (LOU), Allis shad (ALA) and twaite shad (ALF), anchovy (ANC), three-spined stickleback (EPI) and sprat (SPT). It is apparent that Nilsson's pipefish (SYNJ and SYNA) is associated with pelagic species. All these species are characteristic of the third group of the AHC. On the top part of the graph, we can find juveniles smelt (EPEJ) and then going down along axe 2 there is an heterogeneous group composed of sole (SOL), younger stage of flounder (FLEJ), older stage of smelt (EPEA), ovigerous white shrimp (CRBO) and eel (ANG). This heterogeneous group is associated with the second class stemming from the classification.

\subsection{Comparison with the data of 2000}

It is noted that some species caught in 2000 were not sampled during the reference period 1991-98: five-bearded rockling, Ciliata mustela, shi drum, Umbrina cirrosa, garpike, Belone belone, herring, Clupea harengus and mosquitofish, Gambusia affinis. The value of the RV coefficient between the table of data sampled in 2000 and the reference table was 0.857 . The variables (species) of the table of data sampled in 2000 were projected on the first plane of the CoA processed on the reference table (Fig. 7). This projection allows us to study possible differences between species organization (or typology) in 2000 and reference species organization by analysing relative positions of species plots on the factorial map (Fig. 7). Some "shifts" are of note for some species such as adult and juvenile smelt (EPEA and EPEJ), for 
instance. A measure the deviation to the reference situation for the species is provided by computing distances between plots for the reference situation and plots corresponding to 2000 (Fig. 8).

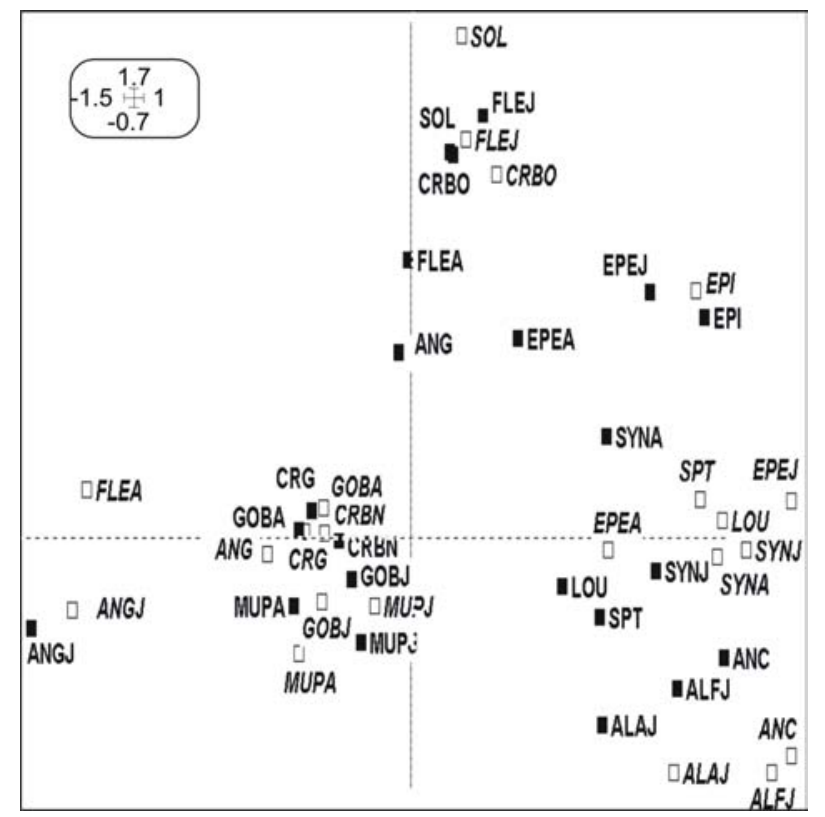

Figure 7. Projection of the species codes from the table of data sampled in year 2000 on the first plane (53.3\% of variance) of the CoA processed on the reference table. (n) species codes of the reference table; () species codes of year 2000.

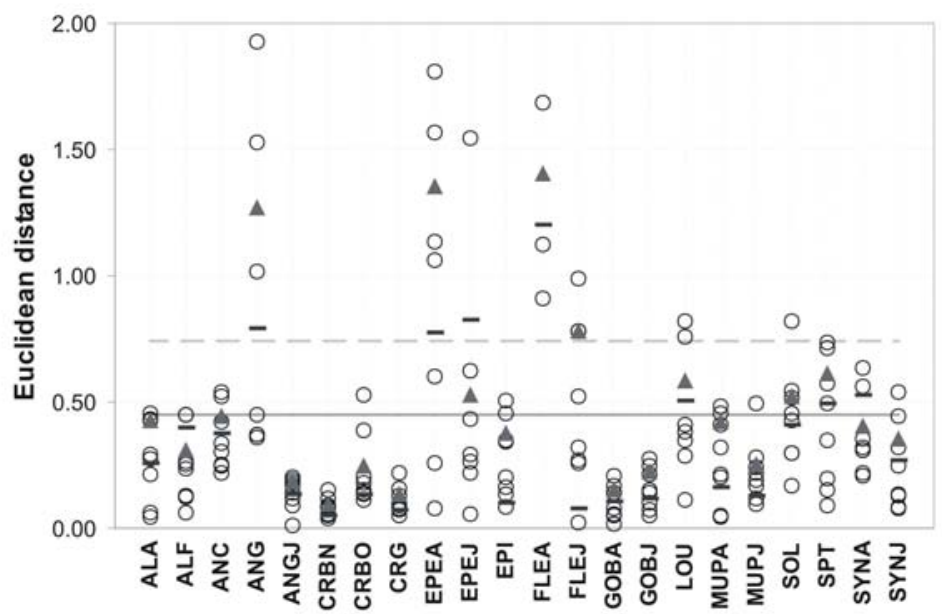

Figure 8. Scattergrams of the Euclidean distances. Dashes (-) represent distances between plots for the reference map and plots corresponding to the sampling of 2000. Circles $(O)$ represent distances between plots for the reference map and illustrative plots corresponding to each year of sampling for each species. Triangles (5) represent 3rd-quartile for each distribution. The line (-) represents the $3 r d-$ quartile for the overall distribution and the dotted line represents the 90th centile for the overall distribution.

The positions of species were considered by plotting them for the different years of the reference period 1991-98 (Fig. 9) as too were thecomputed distances between these illustrative plots and the plot representing the species on the factorial map (Fig. 8). Points corresponding to the positions of glass eel (ANGJ) and white shrimp (CRBN) spread into small areas and the standard deviations of the distances are low whereas the plots for smelt (EPEA and EPEJ) and adult flounder (FLEA) are much more scattered and the standard deviations of the distances are 
much higher. Fig. 8 displays on the scattergrams of the distances on the factorial map for each species some of the limits that can be computed to evaluate deviation from the reference situation: $3^{\text {rd }}$-quartile for each distribution, $3^{\text {rd }}$-quartile and $90^{\text {th }}$ centile for the overall distribution. These 3 limits are presented here only as illustrations.

The cases of glass eel, flounder and smelt will be discussed as examples.

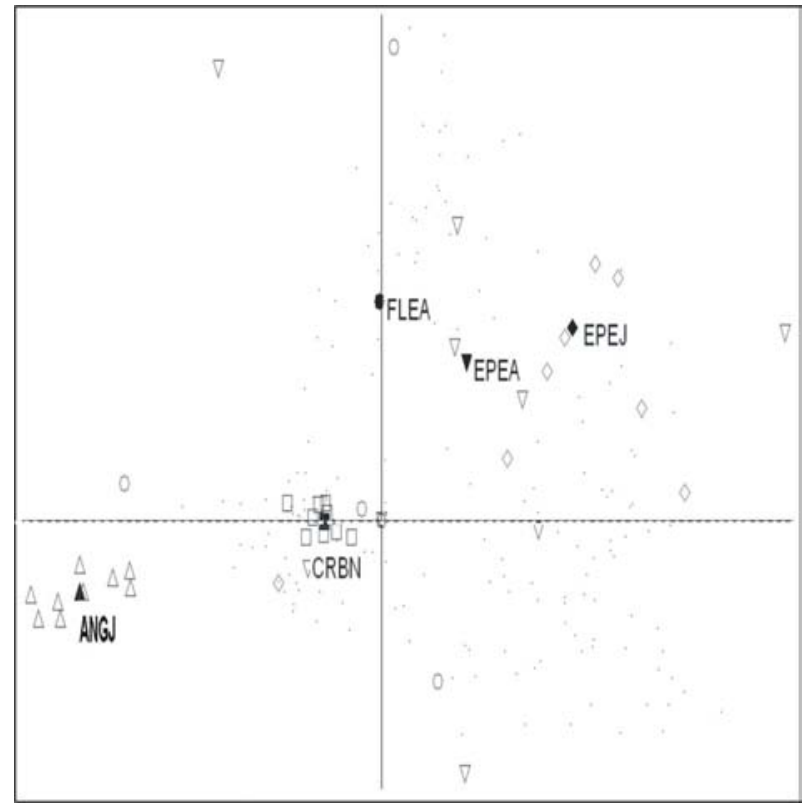

Figure 9. Projections of the species codes for each of the eight years of the reference period (empty symbols) on the CoA processed on the reference table (full symbols). Only few species are selected. Only points symbolize the others.

\subsection{Temperature, salinity and flow}

In addition to the elements of the climatological context specified earlier, mean monthly temperature, salinity and river flow values in 2000 were plotted as an interpretation element to compare to the interval [mean monthly value \pm standard deviation] for the 1991-98 period (Fig. 2). No real obvious differences between 1991-98 and 2000 have been noticed.

\section{Discussion}

\subsection{The reference seasonal pattern: ecological inference and variability}

The contribution of each year of sampling to the construction of the compromise table is well balanced. There is no high weight or $\operatorname{Cos}^{2}$ value. This indicates that each table (year) has its own structure but a common structure in each one can be identified. That means that annual variability existed but seasonal variability is unquestionably the most important one for species composition of the Gironde estuarine assemblages. It has been discussed in many estuaries (Potter et al., 1986; Methven et al., 2001; Thiel and Potter, 2001) and it is clearly shown by the double structuring in space and time that appears in the compromise analysis. The scores of months are ordered and their trajectory draws an annual cycle. In relation to this, the position of species on the factorial plane seems completely in agreement with the moment they occur in the mesohaline part of the estuary. For instance, the position of some species such as diadromous species on the compromise plane is particularly revealing of the seasonal pattern. A typical example is the one of glass eels that arrives between December and January for most of them (Elie and Rochard, 1994).

With the shad (Alosa sp.), individuals sampled during this monitoring programme are young of the year and are as part of their life-cycle utilising the estuary before emigrating to the sea during summer. Both the twaite shad and in autumn for Allis shad are recorded in the 
Gironde estuary. The maximum abundance of smelts in the Gironde estuary is earlier in summer (May, June and July) and particularly in June when the young of the year arrive in the estuary and are recruited by our sampling gear. Like gobies or white shrimps, flounders and mullets are more or less present all year long in the estuary in which they execute migrations, in the upper part for flounder (up to the first dam) and in the downstream and middle part for the thin-lipped grey mullet. They are so plotted near the intersection of the axes. Conversely, the three-spined stickleback, which is a freshwater species in the Gironde estuary (Lobry et al., 2003), is frequent in the adjacent marshes and it moves towards the stream bed in low water period (July to September in the Gironde estuary).

For diadromous fish as for others, the position of the species on the compromise plane can be related, first, to the moment when they arrive in the area of influence of the sampling zone in the estuary. Fish and shrimps populations thus succeed one another in this part of the estuary during the year. The fish and shrimps communities in the estuary can thus be split up into a succession of fish and shrimps populations. Three main ecological seasons can be identified corresponding to the three groups described in the commented results of the AHC (see table III). Three distinctive assemblages can be related to these ecological seasons. It is of note that the characteristic species of spring and autumn are also associated with more or less permanent species such as white and brown shrimps, goby and, to a lesser extent, mullet or even flounder. Actually, only few species are constant in the estuary during a year. The most frequent are the sand goby and the white shrimp. They are plotted near the centre of the graph.They are present all year long in the samples but they are probably more characteristic of cold months because the number of other species in the area is much less important.

It is assumed that this can be related to seasonal variations of water flow (Le Pape et al., 2003b), which affects level of salinity, turbidity (Sottolichio and Castaing, 1999) and temperature. These hydrological factors are probably the most important structuring factors for estuarine biological communities and especially for fish and shrimps (Rebelo, 1992; Castel, 1993; Thiel et al., 1995; Maes et al., 1998; Marshall and Elliott, 1998).

This temporal pattern was closely related to an ocean-river gradient. Indeed, marine species such as Nilsson's pipefish, bass, anchovy or sprat reach the upper part of the marine estuary from the ocean when the river flow is weak and salinity intrusion penetrates fairly upstream i.e. during summer and early fall in the Gironde estuary. In this spatial context, the case of shad is interesting. The individuals of the sampled lifestage come from the river but some years, a decreasing gradient of the density of juvenile shads to the upstream transect is noticed. This leads one to suppose that the distribution of the population is downstream the area of influence of the sampling protocol.

The position of constant species, and especially goby and white shrimp, in relation to transects 3 and 4 on the plane could be surprising. But, even if they are estuarine resident species able to achieve their life cycle in the estuary, they migrate up to the lower part of the rivers in summer (Aurousseau, pers. comm.; Boigontier and Mounié, pers. comm.). The centre of inertia of the population is thus situated upstream. It is also the case for juvenile sole, which use particular settlement areas in the oligohaline zone of the estuary as nurseries like in the Loire estuary (Elie and Marchand, pers. comm.).

The estuary is thus a place of transition and a migratory route and can be regarded as a transitory key habitat as defined by Gili (2002). The succession of populations following cycles in space and time can be studied in term of a biomass flux in the environment. This remark can be investigated while analysing energy budget in the ecosystem. In this connection, it is of note that surface sites were associated with downstream stations and riverbed sites were associated with upstream stations. This is probably due to the vertical distribution of most of the marine species which are pelagic whereas most of resident species are benthic or demersal (sand goby, white shrimp and brown shrimp). So, a kind of biomass transfer in the water column occurs between warm months and cold months. The periods of high salinity and low flow rates in the estuary allow marine species to spread out in the environment. From a trophodynamical perspectiveit is apparent that abundance peaks of phytoplankton and zooplankton occur during spring, abundance peak of mysids occurs during summer and an other phytoplanktonic bloom 
occurs in late autumn (Castel, 1993; David et al., 2005). That could constitute an incentive element for these marine pelagic species that are rather planktivorous for most of them. Conversely, even if there is an abundance peak of benthos during summer, density values are relatively high all year long allowing benthic species, that are generally more omnivorous, to feed on benthic invertebrates even during winter. These assumptions suggest that there is trophic suitability of the environment.

Considering this hypothesis, the position of smelt, mullet and Nilsson's pipefish need further investigation. Although the first two are pelagic species, their feeding behaviour leads them to swim near the estuary bed. As such, they are plotted in the part of the graph rather associated with bottom stations. Conversely, even if, at first, it could appear surprising, the association of Nilsson's pipefish with pelagic species in the factorial map is explained by important current velocities and lack of aquatic plants in the Gironde estuary, that force it to reside within the water column.

In the context described above, loading the trajectories of the species plots for the different years of the 1991-98 period on the reference factorial map may represent the pattern's variability for each species. For most of them, points are located in quite small areas (Fig. 9). It is particularly true for white shrimp and glass eel. It is not really surprising for white shrimp which was constant in the estuary all the years and all year long. For glass eel, it probably means that the moment it entries in the Gironde estuary is very narrow from year to year. The estuary is accessible for it at only one period of the year due to the particular life cycle of Anguilla anguilla. Conversely, plots spread into a larger area for smelt and flounder. The occasions that these species are present within the upper part of the marine estuary are probably less characteristic. For instance, no adult flounders were sampled in the part of the estuary concerned by the protocol described above in 1991-94 and in 1997. In 1995, flounders were caught in September and November, in February, June, July, August and November in 1996 and in May and June in 1998. The ecology of flounder is not well known in the Gironde estuary so it is quite uneasy to make a parallel between these data and the life cycle of Platichtys flesus. Furthermore, the sampling gear used is probably not efficient for sampling flounders due to the runners that keep the frame $0.2 \mathrm{~m}$ from the bed. For smelts, it is quite different. The population have known high fluctuations in abundance during the reference period (Pronier and Rochard, 1998) making some sampling campaigns not really representative of the species behaviour.

\subsection{How to use the reference pattern?}

It was proposed within this study, to use the pattern observed through the compromise analysis as a reference pattern. As an example of a comparison with the reference situation, we used data sampled in 2000. First, we noticed that some species were sampled in 2000 whereas they were never caught during the reference period (1991-98). This could be due to particular hydrodynamic or environmental conditions and particularly to high values of water flood but there is no evidence of significant deviation in water temperature, salinity and river flow between the two periods. Moreover, there is a significant year-to-year variability for copepods and mysids in the estuary (David et al., 2005) but correlation between abundances of trophic resources in the one hand and fish and shrimps assemblages in the other hand have not been properly explored for the two periods. This could be a relevant hypothesis to verify.

The value of the RV coefficient between reference table and the year 2000 table is high: 0.857. That means that, even if local differences exist, the structures of the fish and shrimps assemblages in the estuary were very similar in 2000 and in 1991-98. Projection of the variables (species) of 2000 on the reference first plane allows us to detect deviations between the considered situation and the reference by interpreting in an ecological way distance between plots representing species in the two contexts. For instance some species seems to have appeared earlier (e.g. eel) or later (smelt) in this part of the estuary in 2000 rather than in 199198. This technique seems promising in order to pick out possible anomalies in the pattern of fish and shrimps successions. However, the scattering of the species' trajectories has to be taken into account when interpreting distances between plots representing 2 situations in exactly like manner the standard deviation is considered when comparing 2 values. So, it can be quite uneasy to characterize and interpret in a quantitative way real deviations from the reference 
situation for species, such as flounder, which plots on the reference factorial map are scattered. The use of Euclidean distances is proposed here as an example of quantitative measure for variability and deviation. It seems to be a relevant and a fairly simple and pragmatic mathematical tool in this context. But, a definition of bounds for the values of the calculated distances is necessary to characterize whether a deviation from the reference situation is significant or not. In fact, the problem of the limits is an open problem which probably needs consultations with specialists for given situations. But, actually, even if it should be associated with other measures, such as abundance monitoring, in order to perceive more single disturbances, it seems that the method could be efficient to detect trends in changes in the use of space by species. Nevertheless, it would be necessary to go much further in the interpretation and in ecological inferences in order to characterise whether the "new" situation is better or not.

It is of note that the technique is fairly robust to the type of data used. For instance, STATIS analysis processed on the same tables with abundance of species without logtransformation or in classes of abundance led to similar typologies (unpublished data). Abundance was then expressed in number of individuals per $1,000 \mathrm{~m}^{3}$ of filtered water and the classes were calculated using quartiles for each species (we defined 5 classes with the first one was absence of the species in the sample). The double structuring in space and time appeared also in these two analyses even if it was less clear with data in abundance.

\section{Conclusions}

Describing a strong seasonal pattern for fish and shrimp populations within an estuary is not a unique approach but the analysis described here has provided the basis for further development.

First, the ACT-STATIS method as used in the present work appears to be an original and powerful modern multivariate technique to investigate dynamic patterns in the structure of faunistic assemblages in a high variable environment such as an estuary. Its main advantage is to allow us to focus on the stable part of the spatial and temporal variations of the fish and shrimps assemblages. This enabled us to describe a pattern in the use of space in the estuary by the small fish and shrimps fauna over a fairly long period ( 8 years). The obtained pattern is common to every matrix taken into account i.e. to every year of sampling. It thus describes an ordinary functioning of the fish and shrimps community in the estuary over the considered period. 1991-98 is an "actual" period during which no changes in the sampling protocol occurred. Choosing such a period as a comparison point can be particularly relevant, especially when reliable and precise historical data about the system without any perturbations are not available.

The described pattern was thus considered as a reference. The reference conditions constructed in this study are possible only for water bodies which have annual high quality time series biological data are available over a fairly long period. The Gironde estuary appears as an interesting area to experiment functional approach of the reference situation concept. But it could be envisaged that this approach could be developed for other areas where less data are available. It may also be refined as a method in order to implement several selected estuarine areas using data from WFD monitoring schemes. In this way, each selected areas would be considered representative as an estuarine type.

This paper focused upon the spatial and temporal variations in species composition of fish and shrimps populations in the mesohaline and oligohaline parts of the estuary. In particular, seasonal variability was assed. Favorability of the areas was discussed in terms of hydraulic regime but may also be discussed in terms of trophic resource availability. As such, the next step in this functional approach must be in characterizing structuring factors of species assemblages. In this way multivariate analysis techniques such as Canonical Correspondence Analysis (Ter Braak, 1986; Lebreton et al., 1991) are an interesting and pertinent method to explore. A more expansive investigation, such as that suggested by Able (Able, 2005), would be necessary in order to improve the understanding of the connectivity between estuarine and coastal habitats and of the factors that influence the ingress of marine fish in the estuarine environments. 


\section{Acknowledgements}

We would like to thank Jean-François Bigot, Bernard Ballion, Christine Gazeau, Gérard Castelanaud, Michel Girardin and all the other persons who took part in the different sampling campaigns. The data used in this study were collected thanks to support of EDF (The Blayais Nuclear Power Plant and Direction des études et des recherches, Département Environnement) and Cemagref (Ecological State Programme, research grant "Estuaires : Typologie et évaluation de l'état écologique des milieux de transition de type estuarien à partir du cas de la Gironde "). This study is part of the ECOBAG (Ecology and Economics of the Garonne basin) programme. And finally, many thanks to Isabelle Ortusi for her help, to Yves Désaunay for his sympathy and to Steve Coates for checking the English

\section{References}

Able, K.W., 2005. A re-examination of fish estuarine dependence: Evidence for connectivity between estuarine and ocean habitats. Estuarine, Coastal and Shelf Science 64, 5-17.

Baran, E., 1995. Dynamique spatio-temporelle des peuplements de poissons estuariens en Guinée : Relations avec le milieu abiotique. TDM 142, Editions ORTSOM, Paris, 236 pp.

Blanc, L. and Beaudou, B., 1998. Stabilité temporelle des structures spatiales des peuplements piscicoles des régios Languedoc-Roussillon et Provence-Alpes-Cote d'Azur. Bulletin Français de la Pêche et de la Pisciculture 348, 23-45.

Blanc, L., Chessel, D. and Doledec, S., 1998. Etude de la stabilité temporelle des structures spatiales par analyses d'une série de tableaux de relevés faunistiques totalement appariés. Bulletin Français de la Pêche et de la Pisciculture 348, 1-21.

Castel, J., 1993. Long-term distribution of zooplankton in the Gironde estuary and its relation with river flow and suspended matter. Cahiers de Biologie Marine 34, 145-163.

Claridge, P.N., Potter, I.C. and Hardisty, M.W., 1986. Seasonal changes in movements, abundance, size composition and diversity of the fish fauna of the severn estuary. Journal of the Marine Biological Association of the United Kingdom 66, 229-258.

Costa, M.J., Cabral, H.N., Drake, P., Economou, A.N., Fernadez-Delgado, C., Gordo, L., Marchand, J. and Thiel, R., 2002. Recruitments and production of commercial species in estuaries. In: Elliott, M. and Hemingway, K.L. (Eds), Fishes in estuary. Blackwell Science Ltd, London, pp. 54-123.

David, V., Sautour, B., Chardy, P. and Leconte, M., 2005. Long-term changes of the zooplankton variability in a turbid environment: the Gironde estuary (France). Estuarine, Coastal and Shelf Science 64, 171-184.

Elie, P. and Rochard, E., 1994. Migration des civelles d'anguilles (Anguilla anguilla L.) dans les estuaires, modalités du phénomène et caractéristiques des individus. Bulletin Français de la Pêche et de la Pisciculture 335, 81-98.

Elliott, M. and Dewailly, F., 1995. The structure and components of european estuarine fish assemblages. Netherlands Journal of Aquatic Ecology 29, 397-417.

Elliott, M., O'reilly, M.G. and Taylor, C.J.L., 1990. The Forth estuary: a nursery and overwintering area for North Sea fishes. Hydrobiologia 195, 89-103.

EU, 2000. Parliament and Council Directive 2000/60/EC of 23rd October 2000. Establishing a Framework for Community Action in the field of Water Policy. Official Journal PE-CONS 3639/1/00 REV 1, Brussels, 72 pp.

Foucart, T., 1978. Sur les suites de tableaux de contingence indexés par le temps. Statistique et Analyse des données 2, 67-84.

Frontier, S., 1983. Stratégies d'échantillonnage en écologie. Les presses de l'université de Laval, Québec, $494 \mathrm{pp}$.

Gaertner, J.-C., Chessel, D. and Bertrand, J., 1998. Stability of spatial structures of demersal assemblages: a multitable approach. Aquatic Living Resources 11, 75-85.

Garcia, S.M., Zerbi, A., Aliaume, C., Do Chi, T. and Lasserre, G., 2003. The ecosystem approach to fisheries. Issues, terminology, principles, institutional foundations, implementation and outlook. FAO, Fisheries Technical Paper, 443.

Gili, J.M., 2002. Towards a transitory or ephemeral key habitat concept. Trends in Ecology and Evolution 17,453 .

Lavit, C., Escoufier, Y., Sabatier, R. and Traissac, P., 1994. The ACT (STATIS method). Computational Statistics \& Data Analysis 18, 97-119.

Le Pape, O., Chauvet, F., Mahévas, S., Lazure, P., Guérault, D. and Désaunay, Y., 2003a. Quantitative description of habitat suitability for the juvenile common sole (Solea solea, L.) in the Bay of 
Biscay (France) and the contribution of different habitats to the adult population. Journal of Sea Research 50, 139-149.

Le Pape, O., Chauvet, F., Desaunay, Y. and Guerault, D., 2003b. Relationship between interannual variations of the river plume and the extent of nursery grounds for the common sole (Solea solea, L.) in Vilaine Bay. Effects on recruitment variability. Journal of Sea Research 50, 177-185.

Lebreton, J.D., Sabatier, R., Banco, G. and Bacou, A.M., 1991. Principal component and correspondance analyses with respect to instrumental variables : an overview of their role in studies of structure activity and species - environment relationships, in : Applied multivariate analysis in SAR and environmental studies, Devillers, J. and Karcher, W. (Eds). Kluwer, Dordrecht, pp. 85-114.

Lekve, K., Stenseth, N.C., Gjosaeter, J. and Doledec, S., 2002. Species richness and environmental conditions of fish along the Norwegian Skagerrak coast. ICES Journal of Marine Science 59, 757769.

Lobry, J., Mourand, L., Rochard, E. and Elie, P., 2003. Structure of the Gironde estuarine fish assemblages: a European estuaries comparison perspective. Aquatic Living Resources 16, 47-58.

Maes, J., Taillieu, A., Van Damme, P.A., Cottenie, K. and Ollevier, F., 1998. Seasonal patterns in the fish and crustacean community of a turbid temperate estuary (Zeeschelde Estuary, Belgium). Estuarine, Coastal and Shelf Science 47, 143-151.

Marshall, S. and Elliott, M., 1998. Environmental influences on the fish assemblage of the Humber estuary, UK. Estuarine, Coastal and Shelf Science 46, 175-184.

Mc Lusky, D.S., 1981. The Estuarine Ecosystem. Wiley, New York, 150 pp.

Methven, D.A., Haedrich, R.L. and Rose, G.A., 2001. The fish assemblage of a Newfoundland Estuary: diel, monthly and annual variation. Estuarine, Coastal and Shelf Science 52, 669-687.

Potter, I.C., Claridge, P.N. and Warwick, R.M., 1986. Consistency of seasonal changes in an estuarine fish assemblage. Marine Ecology Progress Series 32, 217-228.

Pronier, O. and Rochard, E., 1998. Fonctionnement d'une population d'éperlan (Osmerus eperlanus, Osmériformes Osmeridae) située en limite méridionale de son aire de répartition, influence de la température. Bulletin Français de la Pêche et de la Pisciculture 350-51, 479-497.

Rebelo, J.E., 1992. The Ichthyofauna and abiotic hydrological environment of the Ria de Aveiro, Portugal. Estuaries 15, 403-413.

Salomon, J.-N., 2002. L'inondation dans la basse vallée de la Garonne et l'estuaire de la Gironde lors de la "tempête du siècle" (27-28 décembre 1999). Géomorphologie : relief, processus, environnement 2 , 127-134.

Sottolichio, A. and Castaing, P., 1999. A synthesis on seasonal dynamics of highly-concentrated structures in the Gironde estuary. Comptes rendus de l'Académie des Sciences Série II Fascicule aSciences de la Terre et des Planètes 329, 795-800.

Tank, A., Wijngaard, J.B., Konnen, G.P., Bohm, R., Demaree, G., Gocheva, A., Mileta, M., Pashiardis, S., Hejkrlik, L., Kern-Hansen, C., Heino, R., Bessemoulin, P., Muller-Westermeier, G., Tzanakou, M., Szalai, S., Palsdottir, T., Fitzgerald, D., Rubin, S., Capaldo, M., Maugeri, M., Leitass, A., Bukantis, A., Aberfeld, R., Van Engelen, A.F.V., Forland, E., Mietus, M., Coelho, F., Mares, C., Razuvaev, V., Nieplova, E., Cegnar, T., Lopez, J.A., Dahlstrom, B., Moberg, A., Kirchhofer, W., Ceylan, A., Pachaliuk, O., Alexander, L.V. and Petrovic, P., 2002. Daily dataset of 20th-century surface air temperature and precipitation series for the European Climate Assessment. International Journal of Climatology 22, 1441-1453.

Ter Braak, C.J.F., 1986. Canonical correspondence analysis: a new eigenvector technique for multivariate direct gradient analysis. Ecology 67, 1167-1179.

Thiel, R. and Potter, I.C., 2001. The ichthyofaunal composition of the Elbe Estuary: an analysis in space and time. Marine Biology 138, 603-616.

Thiel, R., Sepulveda, A., Kafemann, R. and Nellen, W., 1995. Environmental factors as forces structuring the fish community of the Elbe Estuary. Journal of Fish Biology 46, 47-69.

Thioulouse, J., Chessel, D., Dolédec, S. and Olivier, J.M., 1997. ADE-4: a multivariate analysis and graphical display software. Statistics and Computing 7, 75-83. 